\title{
Transdisciplinary research in the cooperation between intercultural philosophy and empirical sciences
}

\author{
HEINZ KIMMERLE
}

\begin{abstract}
This article will examine how philosophy and empirical sciences can cooperate in research. It is presupposed that in philosophy and in the empirical sciences different types of discourses are used. This difference causes a large gap between them, which has to be bridged. Intercultural philosophy is understood as a specific approach to philosophy as a whole. It is necessary to make philosophy fit into a world in which exchanges are happening on a global level in many fields. In the dialogues between the philosophies of different cultures, support is needed from certain empirical sciences for the understanding of the philosophy, which is based on the the participation of philosophers in everyday life and everyday language. Therefore, in addition to the the support by empirical sciences, living in a foreign culture, participating in its life, is necessary for intercultural philosophers.
\end{abstract}

Keywords: Philosophy as a specific discourse, empirical sciences, intercultural philosophy, dialogues between the philosophies of different cultures, relations between empirical sciences.

Disciplines: Trasdisciplinary Studies, Philosophy, Intercultural Philosophy.

\section{Introduction}

The question whether transdisciplinary research is possible between philosophy and empirical sciences needs special attention. The cooperation between philosophy and empirical sciences is principally

- Professor Heinz Kimmerle is an emeritius Professor of the University of Rotterdam in the Netherlands. He is an international specialist in Intercultural Philosophy and has extensive experience in the field of Philosophy as discipline in Africa. He is is actively involved in research with colleagues at the University of Venda in South Africa's Limpopo Province.

TD: The Journal for Transdisciplinary Research in Southern Africa, Vol. 3 no. 1, July 2007, pp. 95-103. 
different from transdisciplinary research, as it is conducted between two or more empirical sciences. Philosophy and empirical sciences are different types of theoretical discourses. The conditions of the possibility of their cooperation and the way in which it can be done have to be examined. This applies to philosophy in general and also to its relation to empirical sciences. This will be discussed in the second paragraph. The problem is more specific where intercultural philosophy is concerned. It is a question within philosophy to determine what is meant by intercultural philosophy. Philosophy has to reflect on the conditions of its work in a time of worldwide exchanges between all cultures and in all the different spheres of life. Paragraph 1 will explain the significance this has for philosophy. Whatever can be said about this question, intercultural philosophy is philosophy in the strict sennse of the word. Therefore, the general determination of the relation between $\mathrm{p} \backslash$ hilosophy and empirical sciences, as formulated in paragraph 2, is applicable to intercultural philosophy. However, this specific way of practising philosophy brings about a specific necessity of cooperation with certain empirical sciences, which goes further than in philosophy in general. Cultural studies, as a whole, are not the only necessary partner to cooperate with. In addition, the sciences of language, history, society, economics and politics deserve consideration. What they have to say is necessary to understand other cultures and the conditions of exchanges between them. In paragraph 3 it is the subject of discussion.

\section{What is meant by 'intercultural philosophy'?}

Intercultural philosophy is not a special discipline within philosophy. Such disciplines are ontology, logic, ethics, theory of knowledge, philosophical anthropology, social philosophy, political philosophy, philosophy of history, philosophy of culture and philosophy of religion. Intercultural philosophy is a dimension of philosophy in all the different disciplines within philosophy. It departs from the conviction that philosophy - in its different disciplines - is not practiced in one culture only (the European-Western culture) or in a restricted number of cultures (Western and Eastern cultures or those who know the art of writing), but in all types of human cultures. All cultures have a certain type of philosophy. Together they form world-philosophy, which has its unity in its different voices. These differences are in style and accentuation of the relevance of certain disciplines. In the West e.g., logic and theory of knowledge, ontology and philosophical anthropology, whilst in sub-Saharan Africa ethics, and philosophy of religion are valued most highly. The most far-reaching difference is whether its practices and its traditions are, primarily based on writing, or on oral communication. Intercultural philosophy enhances exchanges between 
the different types of philosophy in the different cultures. It would be very strange if philosophy stood apart from a world in which exchanges take place between different spheres of life, for example in economy, politics, sciences, art, sport and entertainment. Moreover, exchanges between the philosophies of different cultures are advantageous for all parts. They can learn from each other, enrich each other and broaden their means of solving problems.

The most appropriate form of practicing intercultural philosophy is to organise and lead dialogues on philosophical issues. Dialogues presuppose equality in rank and differences in style and/or in content. Intercultural dialogues are possible in philosophy because there is no hierarchy between the philosophies of different cultures. All of them are on the same level, although, as stated above, they differ in style and content. Compared to the form of intercultural philosophy, in other fields, for instance economy, politics or sciences, the intercultural exchanges are of a different kind. In these fields, one culture can claim a superior status, or prove to be more powerful. Between philosophy and art, however, we find an important similarity. Exchanges in the field of art presuppose the same equality in rank between all cultures as philosophy does. So, real dialogues between philosophies and art-productions of different cultures are possible. They can set an example on how to make exchanges in other fields, where hierarchical relations prevail more dialogical ones.

Needless to say, interculturality in philosophy is intertwined with the problems of multiculturalism. These problems arise from the presence of groups of people from different cultures on the territory of one state or group of states. Thus, intercultural philosophical dialogues are already part of the philosophical practice in one state or one group of states of a certain culture. A clear example of this is African American philosophy in the USA. There are many other endeavours of this kind, for instance the efforts to come to Westernised types of Buddhist or Moslem philosophies in Europe.

The most important characteristics of intercultural philosophy especially when its relation to other sciences or types of theory is under discussion - are the fact that it is philosophy in the strict sense of the word. It is not an empirically underpinned science. It has only thinking as a basis of its theoretical discourse, which means firstly logical thinking, but secondly also using language in a general way, which has the evidence of being true in itself. In Western philosophy, it uses concepts and a relation between them, which is also conceptually conceived. Concepts are carefully and rationally defendable generalisations of words, taken from everyday language, or some professional or scientific language. A discourse, which is built up by concepts and conceptually structured relations between them, can be characterised as argumentation. Philosophies of non-Western 
cultures sometimes use language in a less conceptual, more narrative way. Nevertheless, they come to the same kind of generalisation as a conceptual language and they build up argumentations in the full sense of the word. For every type of philosophy, it is decisive that it does not seek or obtain any help or support for its truth claim from outside, especially not from any type of authority.

Hegel has argued that the beginning of philosophy cannot be marked clearly. The first sentence of a philosophical discourse is already philosophy. The last sentence of a discourse, which is meant to introduce philosophy, is as such not yet philosophy. Therefore, a philosophical introduction to philosophy is not possible. ${ }^{1}$ This situation turns out to be paradoxical when Hegel himself writes introductions to his philosophical works. Derrida has pleaded for an acceptance of this paradoxical situation. He tries to support this acceptability by analysing what a Hors d'oeuvre is. Preceding the meal, it is outside the meal. At the same time, as the first part of the meal, it is part of the meal. The same relation can be stated between Hors livre and the philosophical book. This leads to the conclusion that the impossible task of introducing philosophy simply needs to be done. ${ }^{2}$

\section{How can philosophy relate to empirical sciences?}

Philosophy begins with itself. To make its start possible, it presupposes, as we have seen, everyday language, professional language and/or scientific languages. It needs these languages and it uses them in a specific way. However, they are not a constitutive part of philosophy itself. They are, and they remain, outside of what philosophy is. Hegel formulates it as follows: When a philosophy is created, it needs and uses building material. Its task is to grasp its time in concepts. The building material is the language and the representations of the time. What makes a discourse philosophical is not the building material,

1 GWF Hegel, Womit muß der Anfang der Wissenschaft gemacht werden? in G Lasson (Ed.), Wissenschaft der Logik, (Meiner, Hamburg, 1963), pp. 51-64. Here, Hegel is using a different set of terminology. In this terminology, philosophy, if it strictly proceeds according to its principles, is science. As science of science, it is science in a different and more emphatic sense than empirical science. 
but the way in which it is used. ${ }^{3}$ We can find a description of how the words of everyday language are generalised and transformed into concepts in Aristotle's writings. He often departs from 'what is said' and then clarifies what exactly somebody means when something is said. Thus, he comes to the general meaning of certain words of everyday language. He transforms words of everyday language into concepts. In a similar way, we can see in the practices of non-Western philosophies how words of everyday language, religious language or scientific languages, are used in this general sense. This statement remains valid when the practices of non-Western philosophies are embedded in other discourses, for instance in religious, moral or poetical discourses. For intercultural philosophy, it is important that the process of generalisation, as it is brought about in Western philosophy by forming concepts, has a full equivalent in the practices of coming to a general use of words and connections between words in non-Western philosophies.

The process of coming from a not (yet) philosophical discourse to a philosophical one, to the typical way of generalisation as we have described it, does not happen only once. It needs repetition. The hermeneutic circle is an apt model to illustrate how this repetition works. Those who think in a philosophical manner are confronted with non-philosophical languages, for instance languages of empirical sciences, and transform parts of it into concepts or corresponding forms of generalised speaking. After having absorbed or processed these language parts, they need more of it and subsequently transform other parts of the language into its philosophical use.. The process of conceptualisation or generalisation is now easier because the competence in using this type of language has increased. This usually happens many times. The process comes to a provisional end when a portion of a non-philosophical language, for example a language of an empirical science, which forms a meaningful entity, has been absorbed. I will give concrete examples in the next paragraph, when the relationship between intercultural philosophy and certain sciences is examined.

It is clear, at this stage, that the relationship between philosophy and the language of an empirical science cannot be merely described as interdisciplinary research. The philosophical discourse and the prephilosophical discourse of an empirical science cannot be mixed. Every time non-philosophical parts of the language of an empirical science are incorporated into a philosophical discourse, an infinite gap has

3 GWF Hegel, Differenz des Fichte'schen und Schelling'schen Systems der Philosophie, in Gesammelte Werke, vol 4: Jenaer Kritische Schriften, (ed. H. Buchner/O. Pöggeler, Meiner, Hamburg, 1968), pp. 9-12. 
been bridged. The process of translation from one natural language to another is already characterised by Derrida as bridging this kind of gap. Referring to Benjamin and Schelling, he claims that God is in play for this process. Therefore, he calls his article 'Théologie de la traduction'. ${ }^{4}$ He takes the translation from the language of one science to that of another, as it is described by Schelling, as a model for the problem of translation in general. In his Vorlesungen über die Methode des akademischen Studiums from 1803, Schelling says that the translation from the language of one science to that of another, is impossible in principle, but that it needs to be done nonetheless because all the sciences belong together within the whole of the academy. For Schelling the higher unity of the academy is a symbol for the highest unity of nature and intelligence, which can be experienced as 'community with God'.

Schelling does not depart from a principle difference between philosophy and empirical sciences. What he says about the impossible task of translation between sciences, including philosophy as a science, that has to be done nonetheless, is applied here to the exchange between the specific type of philosophical language and nonphilosophical languages of everyday life and of empirical sciences. By making this difference we follow Hegel's, rather than Schelling's conception of philosophy, which is regarded as a discourse that is principally different from empirical sciences. Let us work out how this difference is to be understood in more detail.

The truth of what is said is usually judged by measuring it through empirical data, particularly in empirical sciences. This is no longer the case in philosophy. A completely different way of defending a truth claim is at stake, which does not go outside the philosophical discourse. Of course, philosophy does, or must, correspond to the facts. But it corresponds to them in its own way. Facts in, and for, philosophy are not facta bruta - facts independent from their general meaning and the general interconnectedness of their meanings. For Hegel, therefore, only what is 'rational' or part of the explanation of this kind of general meaning is 'real', so that also the reverse can be stated: 'what is real is rational'. ${ }^{5}$

Thus, the stepping over from a pre-philosophical to a philosophical type of discourse cannot be justified from outside, but has its justification in itself. A transcendere in the literal sense of the word takes place when parts of a pre-philosophical language, for instance

4 J Derrida, Théologie de la traduction, in Du droit à la philosophie, (Galilée, Paris, 1990), p. 371-394.

5 GWF Hegel, Grundlinien der Philosophie des Rechts (ed. J. Hoffmeister, Meiner, Hamburg 1967), p. 14. 
the language of an empirical science, are taken over in philosophy. Therefore, the cooperation between empirical sciences and philosophy has to move its practise of transcendere from disciplines outside of philosophy, to disciplines inside of it. This is, strictly speaking, transdisciplinary research. Let us see how this works concretely by examining the relation of intercultural philosophy to certain empirical sciences.

\section{How intercultural philosophy relates to certain empirical sciences?}

Intercultural philosophy deals with the possibilities and the practices of exchanges between philosophies of different cultures. When it takes its own claims seriously, it deals with the possibilities and practices between the philosophies of all the different cultures. A philosophy uses the language and representations of the specific culture in which it is worked out. To understand the philosophy of a different culture presupposes the necessity to study and come to know the specific conditions of this culture. Usually, understanding comes first, before exchanges can take place. In a more sophisticated hermeneutical sense, however, one can say that understanding the philosophy of a different culture and having exchanges with it are bound together by dialogues, which are practised between the philosophies of different cultures. Actually, the first step of understanding turns out to be dialogical already. When one approaches the philosophy of a different culture, one has already some pre-understanding of that culture. The next step and all the steps thereafter that bring one closer to an understanding of the philosophy of a foreign culture are at the same time an adjustment of this pre-understanding.

The farther away the foreign culture is from the own starting position (not necessarily in the sense of distance in space), the more one has to be cautious in assuming that one has understood something in that culture. This is why I have suggested a 'methodology of listening' for intercultural philosophy. This methodology implies a repeated listening and a provisional state of what one thinks to have understood. ${ }^{6}$ Nevertheless, these are stepping-stones in a dialogue. This dialogue has to be supported by learning about other non-philosophical aspects of the respective culture. Here empirical sciences come in, which provide the intercultural philosophical dialogue with information. The

6 H Kimmerle, Philosophie in Afrika-afrikanische Philosophie. Annäherungen an einen interkulturellen Philosophiebegriff, (Campus, Frankfurt/M., 1991), p. 8 and Die Dimension des Interkulturellen, (Rodopi, Amsterdam/Atlanta, GA 1994), pp. 126128. 
relation between the intercultural philosophical dialogues and the support of them by empirical sciences now deserves examination at closer quarters.

The first obstacle in understanding with such intercultural philosophical dialogues is the foreign language. One has to learn the language of a foreign culture. The result of knowing the language is twofold. It gives access to the ways of living and acting in this culture. This knowledge supports the understanding of the philosophy of the particular culture. There is more, however. The language, the structure of it and the semantic contents of the words, contain information about the philosophical thought of this culture. The sciences of language are helpful for intercultural philosophy because they provide knowledge about the pre-philosophical building material of the philosophy of particular cultures. They are also a direct source for understanding the philosophical thought of foreign cultures.

Secondly, intercultural philosophy has to cooperate with cultural anthropology or ethnology. This science contains information about all fields of life of a foreign culture: customs, rituals, religion and social, economic and political systems, etc. An equivalent of the methodology of listening in intercultural philosophy is the practice of 'participating observation' and the restriction to ethnography, to simply recording the observations. Thus, intercultural philosophy learns a lot about the cultural background of the philosophical thought of that culture. Moreover, cultural anthropology often investigates 'belief systems', which contain philosophy in a direct sense. Here this empirical science, like the languages, supplies information about philosophical thought.

Thirdly, I want to mention historical sciences. It is only possible to understand the present situation of a foreign culture by knowing how the culture has developed. People in any culture refer to their traditions to explain, stabilise, and, if necessary, justify their behaviour. What the ancestors have done and the way in which they have done it is not always correct, but at least it serves as a guideline on how to behave in present times. History can help to understand trends, which will go on in the future. As a part of the different fields of life, which all have their own history, there is also philosophy. And the history of philosophical thought of that culture can be particularly helpful for intercultural philosophy, trying to understand its philosophy and being engaged in dialogues with it. An extraordinary problem arises when communication and tradition are predominantly practised orally in the particular culture. The history of the philosophies of cultures of this kind can be reconstructed by learning from oral history in general and from the history of oral literature. However, the history of philosophical thought has its own rules, which have to be sorted out and obeyed. 
Finally, it has to be said that aspects of cultural anthropology are examined more closely by sciences that deal with them: sciences of religions, of social relations, of economic structures and of political life. Philosophical thought rather often is embedded in other types of discourse, as for instance in religious discourse. Then it is available in the practice and in the scientific explanations of the religion of a certain culture. It has to be made explicit and clarified in its philosophical character. As far as social relations are concerned, the structure of the communities is important, and the meaning which the community has for living and thinking. From the research of social sciences in this field, the self-understanding of people in a certain culture can be reconstructed, which is philosophically directly relevant. The information about the organisation of work contains valuable knowledge of the stratification of the society. There is no doubt that philosophical thought is influenced heavily by the information about these conditions of social relations and economic structures. Intercultural philosophy has to take note of that. The research on political life in a certain culture is similarly important for intercultural philosophy. The system of government, the participation of the population in political processes and the ways of decision-making reveal much about the mutual dependencies between people. These factual relations give insight into the background of the political philosophy of that culture.

We can conclude that the cooperation between empirical sciences, which deal with foreign cultures and intercultural philosophy, is manifold. Intercultural philosophical dialogues need support from the empirical sciences for the understanding of the philosophical work, which is based on the own culture. The language and the everyday knowledge of the own culture is primarily familiar to the philosopher and need not be provided by certain sciences. In the end, intercultural philosophy is dependent on this kind of familiarity with the cultures, which are partners in its dialogues. To live in and experience the lifestyle of a culture where philosophical dialogues should take place, or are already taking place, is particularly important. Transdisciplinary research in the cooperation between empirical sciences and intercultural philosophy cannot fully replace the own intercultural experience and the intercultural competence, which flows from it. 